\title{
Physical and chemical mutagenesis in Linum usitatissimum L. to induce variability in seed germination, survival, and growth rate traits
}

\author{
Irfan Ahmad Bhat ${ }^{1 *}$, Umar Jan Pandit ${ }^{2}$, Imtiyaz Ahmad Sheikh³, Zia UI Hassan ${ }^{1}$ \\ ${ }^{1}$ Department of Botany, Safia P.G. Science College, Barkatullah University, Bhopal, Madhya Pradesh, India, ${ }^{2}$ Department of \\ Chemistry, Dr. H.S.G. University, Sagar, Madhya Pradesh, India, ${ }^{3}$ Department of Botany, Dr. H.S.G. University, Sagar, Madhya \\ Pradesh, India
}

Received: 15.05 .2016

Revised: 25.05.2016

Accepted: 02.06 .2016

Published: 02.07.2016

*Address for correspondence: Irfan Ahmad Bhat, Department of Botany, Safia P.G. Science College, Barkatullah University, Bhopal, Madhya Pradesh, India.E-mail: irfannabi31@ gmail.com

\section{INTRODUCTION}

The genus Linum belongs to family Linaceae and comprises over 200 species which exhibit great diversity in karyotype, biochemical, and morphological attributes. The species of the genus are distributed worldwide in habitats ranging from sea level to high altitudes $(9000 \mathrm{~m}$ above mean sea level). Linum usitatissimum L. plant has short tap root system with fibrous branches extending up to $90120 \mathrm{~cm}$ in light soil. Stem of L. usitatissimum L. grows to a height of $30120 \mathrm{~cm}$ and 34 branches or tillers arise from a node near the surface of the ground. Seed types are bushy and profusely branched.

L. usitatissimum L. being a dicotyledonous plant, the first two leaves are cotyledonary and are thick in texture.

Induced mutations pave a path to induce genetic variability in some economically important selfpollinated crops where crossing/hybridization is quite difficult, viz., wheat (Srivastava et al., 2011) and fenugreek (Chaudhary and Singh, 2001; Basu et al., 2008). Hence, utilization of mutagenesis undoubtedly is capable of increasing genetic variability in a number of crops as reported by many workers (Mahandjiev et al., 2001; Tai et al., 2007; Khan and Goyal, 2009; Kozgar et al., 2011; Srivastava et al., 2011).

Effects of physical mutagenic studies on this plant were studied by Abidi et al. (1978) while studying the effect of gamma irradiation on seed germination of $L$. usitatissimum $\mathrm{L}$. variety Neelum. The X-rays have wavelength from $0.001 \AA$ and can penetrate deep to cause ionization which results in the formation of free radicals (extreme reactive and containing unpaired electrons). Chemical mutagens such as hydroxylamine (HA) react with cytosine at $\mathrm{NH}$ group and form hydroxyl cytosine which pairs with adenine instead of guanine. 5amino acridine (AA) is planar (flat molecule)-like purine bases and at low concentration can be inserted or intercalated between bases of DNA helix, which stretches distance between adjacent base pairs and distorts the DNA strand.

We have taken the present investigation on induced mutagenesis in L. usitatissimum L. using gamma rays, X-rays, $\mathrm{HA}$, and AA to study mutagen sensitivity of L. usitatissimum L. against varying dose rate in immediate generation. 


\section{MATERIALS AND METHODS}

The physical mutagens (gamma rays and X-rays) and chemical mutagens (HA and AA) were employed in the present study. Gamma ray treatment was given from BHEL Bhopal with 200 curie Co gamma cell at a dose rate of $0.465 \mathrm{Kr} / \mathrm{h}$ at a distance of $100 \mathrm{~cm}$. X-ray treatment was given by X-ray machine at Safia P.G. Science College, Bhopal. HA and 5-AA for the present study were obtained from Merck India.

The seeds of L. usitatissimum L. variety IP-I6 were collected from Jawaharlal Nehru Krishi Vishva Vidyalaya, Jabalpur, Madhya Pradesh, India. The variety IP-I6 is branched flowering after 30 days and maturity in 96 days. Capsules in this variety are an important variety of Madhya Pradesh, India.

The seeds presoaked in distilled water for $17 \mathrm{~h}$ were subjected to doses of gamma rays 10 and $15 \mathrm{Kr}$, X-rays 10 and $15 \mathrm{Kr}$, HA $0.1 \%$ and $0.2 \%$, and AA $0.1 \%$ and $0.2 \%$ along a set of untreated seeds with some moisture content used as a control group. Hundred seeds of each treatment sown at $1 \mathrm{~cm}$ depth in plastic trays ( $23 \mathrm{~cm} \times 27 \mathrm{~cm}$ in height) filled with river sand, red soil, and farm yard manure in the ratio 3:2:1 along with control (containing 100 seeds). Water was applied manually on alternative days, and germination was observed daily for 15 days after sowing. Emergence of coleoptiles was taken as the indication of seed germination. Finally, the overall germination percentage was calculated. After germination, plants from each treatment and control transplanted to experimental field which was ploughed well to ensure good growth of plants in 3 replications. The plant to plant and line to line distance was $12 " \times 12$ ".

The survival percentage was computed in percentage from those plants surviving till maturity out of total number of plants produced through seed germination. Observations were recorded for growth parameters, viz., shoot length $(\mathrm{cm})$, root length $(\mathrm{cm})$, and dry weight (mg) of 20 days old seedling. For this purpose, mean of the data collected for 50 seedlings was taken. Data were analyzed using one-way ANOVA in SPSS software package (17.0).

\section{RESULT AND DISCUSSION}

Table 1 shows seed germination and survival percentage in the control as well as in the treated plants of L. usitatissimum L. variety IP-I6.
Table 1: Effect of various doses of physical and chemical mutagens on seed germination and survival percentages in variety IPI6 of Linum usitatissimum $\mathrm{L}$.

\begin{tabular}{lcc}
\hline Mutagens & Germination $\%$ & Survival \% \\
\hline Control & $98 \pm 3.1798$ & $95 \pm 5.36449$ \\
X-rays $(10 \mathrm{Kr})$ & $71 \pm 3.84419$ & $69 \pm 3.05505$ \\
X-rays $(15 \mathrm{Kr})$ & $69 \pm 2.08167$ & $64 \pm 4.25572$ \\
Gamma rays $(10 \mathrm{Kr})$ & $78 \pm 1$ & $76 \pm 5.17472$ \\
Gamma rays $(15 \mathrm{Kr})$ & $76 \pm 4.70225$ & $72 \pm 7.2111$ \\
HA $(0.1 \%)$ & $64 \pm 4.8074$ & $60 \pm 7.50555$ \\
HA $(0.2 \%)$ & $62 \pm 5.48736$ & $58 \pm 6.06447$ \\
AA $(0.1 \%)$ & $70 \pm 5.54777$ & $68 \pm 7.26483$ \\
AA $(0.2 \%)$ & $67 \pm 6.69162$ & $63 \pm 5.56776$ \\
CD & 7.4 & 11.2 \\
\hline
\end{tabular}

HA: Hydroxylamine, AA: 5-amino acridine

A minimum number of seeds of this variety germinated with $0.2 \%$ HA. This minimum was $62 \%$ against $98 \%$ of control. Seed germination percentage of physical (gamma rays, X-rays) and chemical (HA and AA) mutagens treated seeds was gradually declined linearly with every increase of dose level. Percentage reduction in seed germination might have been due to effect of mutagens on meristematic tissue of the seed. The initiation of seed germination process was also considerably delayed with HA doses.

Statistical analysis of critical difference and standard error (Table 1 ) indicates that all the treatments are significantly effective on germination in comparison to control, except low doses of physical and chemical mutagens which exercised negligible effect.

It is evident from Table 1 that all the treatments of physical and chemical mutagens given to variety IP-I6 of L. usitatissimum L. inhibited the germination process as compared to their respective controls with higher doses of physical and chemical mutagens, and germination was significantly delayed. As the concentration increased, inhibitions of germination were also increased. Hence, all the physical and chemical mutagens found to be as germination inhibitors with varying potential.

Several workers (Akgun and Tosum, 2004; Alcantara et al., 1996; Karthika and Lakshmi, 2006; Khan et al., 2005; Kumar and Mishra, 2004; Thapa, 2004; Toker et al., 2005) reported such behavior of physical and chemical mutagens in different crop plants. Taking into the account of the findings documented by various workers (Chaghtai and Prasad, 1979; Gichner and Veleminsky, 1974; Jain and Agarwal, 1987; Mensah et al., 2007; Nazir et al., 2005; Santos, 1961; Sareen and Koul, 1999) and it is inferred that presoaking renders the seed vulnerable to the effect of physical and chemical mutagens and the germination is inhibited due to biochemical interference of physical and chemical mutagens 
with the physiological activities involved in the process of seed germination. On this parameter, chemical mutagens have more effect in comparison of physical mutagens.

The highest plant survival percentage was 95\% observed in control with $5 \%$ mor tality. Minimum number of plants, i.e., $58 \%$ survived with $0.2 \%$ HA treatment showing $42 \%$ mortality. In this variety (IP-I6), survival percentage and dose rate followed an inverse linear relationship as with higher doses survival percentage was noticeably reduced. The reduction in survival percentage is probably due to toxic effect of mutagens. In this parameter, chemical mutagens have more effect in comparison of physical mutagens. Critical difference and standard error (Table 1) analysis indicate that all treatments employed significantly affected survival of plants as compared to control.

Plant survival percentage decreased in variety IP-I6 of L. usitatissimum L. with increasing doses of physical and chemical mutagens which prove that clear correlation exist in between dose rate and survival of plants. Results of the present work reveal that chemical mutagens, particularly HA, is comparatively more operative to cause the lethality than physical mutagens and acridine. Here, gamma rays seem to be more effective than X-rays.

The reduction in plant survival percentage following with physical and chemical mutagens has been reported by many workers, and results of present investigation regarding survival are in agreement with earlier findings in different plants (Bari, 1971; Cheema and Atta, 2003; Davies et al., 1975; Hussein and Disouki 1975; Kar et al., 1995; Siddiq and Swaminathan, 1968; Singh et al., 2006).

Table 2 shows shoot length mean in $\mathrm{cm}$, root length mean in $\mathrm{cm}$, and dry weight mean in $\mathrm{mg}$ of gamma rays, X-rays, HA, and AA treated plants. In variety IP-I6, highest shoot

Table 2: Effect of various doses of physical and chemical mutagens on growth rate in variety IPI6 of Linum usitatissimum L.

\begin{tabular}{lccc}
\hline Mutagens & \multicolumn{2}{c}{ Length $(\mathrm{cm})$} & Mean dry weight $(\mathrm{mg})$ \\
\cline { 2 - 3 } & Mean shoot & Mean root & \\
\hline Control & $5.3 \pm 0.550757$ & $4.9 \pm 1.12398$ & $1.0 \times 10^{-4} \pm 1.53 \times 10^{-5}$ \\
X-rays (10 Kr) & $5.1 \pm 1.12694$ & $4.7 \pm 1.26623$ & $1.0 \times 10^{-4} \pm 2.65 \times 10^{-5}$ \\
X-rays (15 Kr) & $4.9 \pm 0.793725$ & $4.5 \pm 1.08167$ & $9.0 \times 10^{-5} \pm 2.08 \times 10^{-5}$ \\
Gamma & $5 \pm 0.776745$ & $4.6 \pm 1.34288$ & $8.0 \times 10^{-5} \pm 2.03 \times 10^{-5}$ \\
rays (10 Kr) & & & \\
Gamma & $4.6 \pm 0.608276$ & $4.2 \pm 0.680686$ & $7.0 \times 10^{-5} \pm 2.08 \times 10^{-5}$ \\
rays (15 Kr) & & & \\
HA (0.1\%) & $5.1 \pm 1.02632$ & $4.7 \pm 0.680686$ & $9.0 \times 10^{-5} \pm 2.65 \times 10^{-5}$ \\
HA (0.2\%) & $4.9 \pm 0.793725$ & $4.3 \pm 0.43589$ & $8.0 \times 10^{-5} \pm 1.53 \times 10^{-5}$ \\
AA (0.1\%) & $5.2 \pm 1.09697$ & $4.9 \pm 1.25033$ & $9.0 \times 10^{-5} \pm 3.06 \times 10^{-5}$ \\
AA (0.2\%) & $5 \pm 1.01489$ & $4.5 \pm 0.953939$ & $8.0 \times 10^{-5} \pm 2.52 \times 10^{-5}$ \\
CD & 1.32 & 1.16 & 0.000011 \\
\hline
\end{tabular}

HA: Hydroxylamine, AA: 5-amino acridine length mean was observed in control which was $5.3 \mathrm{~cm}$ while minimum shoot length was observed with $15 \mathrm{Kr}$ gamma rays treatment which was $4.6 \mathrm{~cm}$. In this parameter also, mean and dose rate followed inverse trend, i.e., with higher doses of physical and chemical mutagens, shoot length mean decreased as compared to lower doses. Statistical analysis of critical difference and standard error (Table 2) revealed that all the treatments are effective as compared to control. Among various treatments of physical and chemical mutagens, employed lower doses were found to be comparatively insignificant while higher doses of all the physical and chemical mutagens were found to have significant effect on shoot length.

Highest mean root length was observed in control which was $4.9 \mathrm{~cm}$ while minimum mean root length observed under $15 \mathrm{Kr}$ gamma rays treatment which was $4.2 \mathrm{~cm}$. This parameter also follows the same trend as with higher doses mean value decreases. Critical difference in the standard error analysis (Table 2). Revealed that all the treatments except lower doses of mutagens were effective on root length in comparison to control.

Mean dry weight was found highest in control which was $0.001 \mathrm{mg}$ and lowest mean dry weight was observed in $0.2 \%$ HA treatment which was $0.00007 \mathrm{mg}$. Dry weight mean and dose rate of mutagens followed similar trend with increase in dose rate, dry weight mean decreased as compared to lower doses. Analysis of critical difference and standard error (Table 2) indicated that all the treatments except lower doses significantly affect the dry weight of plant in comparison to control.

Gamma rays, X-rays, HA, and AA reduce the shoot length, root length, and dry weight in variety IP-I6 of L. usitatissimum L. at higher doses. Similar observations were made by several workers in different plants (Chopra, 1972; Davies, 1968; Nerkar, 1970; Pathak and Patel, 1988; Rai, 1971; Singh and Singh, 2007). The results of the present work are in agreement with these early findings. The growth rate showed a gradual recovery from the inhibitory effect of mutagens as it increased with the advance of time period after giving periods. In variety IPI6, dwarf plants were produced due to stunted growth. Different workers hold independent opinion regarding phenomenon on stunted growth (Conger and Stevenson, 1969; Gordan, 1954; Gunckel and Sparrow, 1961).

\section{CONCLUSION}

Among the mutagens used, chemical mutagens (HA and acridine) were found to be more effective in showing 
inhibitory effects as compared to physical mutagens (gamma rays and $\mathrm{X}$-rays). HA treatment shows the highest inhibitory effect on germination and survival of plants. In physical mutagens, gamma rays show more inhibitory effect than X-rays. In growth rate parameter, both physical and chemical mutagens show similar inhibitory effects. However, low doses show negligible effect as compared to control in this variety (IP-I6) of L. usitatissimum L. for growth parameter. The inhibitory effect of mutagens is due to the fact that biological damage increased at a faster rate in higher doses/concentration of mutagens. This study was one step toward exploring the most desirable treatment condition for enhancing mutagen efficiency. Further research is required to determine the effect of other variables such as temperature, $\mathrm{pH}$, and post-treatment on mutagen action through PCRR-APD marker in treated population.

\section{ACKNOWLEDGMENTS}

Authors are highly thankful to Safia P.G. Science College, Barkatullah University, Bhopal, and BHEL Bhopal for providing necessary laboratory facilities.

\section{REFERENCES}

Abidi SH, Ghouse AK, Singh RP. Effect of acute gamma irradiation on the seed germination of Linum usitatissimum L. Variety Neelam. Proceedings of Second Geophytol. Conf. Lucknow, 1978. p. 203.

Akgun I, Tosum M. Agricultural and cytological characteristics of M1 Perennial Rye (Secale montanum Guss.) As effected by the application of different doses of gamma rays. Pak J Biol Sci 2004;7:827-33.

Alcantara TP, Bosland PW, Smith DW. Ethyl methane sulfonate induced mutagenesis of Capsicum annuum. J Hered 1996;87:239-41.

Bari G. Effects of chronic and acute irradiation on morphological characters and seed yield in flax. Rad Bot 1971;11:293-302.

Basu SK, Acharya SN, Thomas JE. Genetic improvement of fenugreek (Trigonella foenumgraecum L.) Through EMS induced mutation breeding for higher seed yield under western Canada prairie conditions. Euphytica 2008;160:249-58.

Chaghtai SA, Prasad VV. Effect of some chemical and physical mutagens on seed germination of Capsicum annuum L. Sci Environ 1979;1:95-6.

Chaudhary AK, SinghVV. Inheritance pattern and growth habit in fenugreek (Trigonella foenumgraecum L.). Indian J Genet Plant Breed 2001;61:369-71.

Cheema AA, Atta BM. Radio sensitivity studies in Basmati rice. Pak J Bot 2003;35:197-207.

Chopra S. Morphological Studies in Niger (Guizotia obyssimicd) with Special Reference to the Effect of 2, 4D and Gamma Rays, Ph.D. Thesis, Agra University, Agra; 1972.

Conger AD, Stevenson HQ. A correlation of seed-ling height and chromosomal damage in irradiated barley seeds. Radiat Bot 1969;9:1-14.

Davies DR. Effects of gamma rays on growth and yield of agricultural crops. I. Spring sown wheat. Radiat Bot 1968;8:17-30.

Davies PJ, Evans WE, Parry JM. Mitotic recombination induced by chemical and physical agents in the yeast Saccharomyces cerevisiae. Muta Res 1975;29:301-14.

Gichner T, Veleminsky J. Influence of caffeine on the genetic effects induced by EMS and on the recovery from the EMS (ethyl methane sulphonate) induced injury in barley. Muta Res 1974;25:305-10.

Gordan SA. Occurrence, formation and inactivation of auxins. Annu Rev Plant Physiol 1954;5:314-78.

Gunckel IE, Sparrow AH. Ionizing radiations: Biochemical, physiological and morphological aspects of their effects on plants. Encyclopedia Plant Physiol 1961;16:555-611.

Hussein HA, Disouki IA. Mutation breeding experiments in Phaseolus vulgaris L. I. EMS and gamma ray induced seed coat colour mutants. Z.P. Flanzenzuchtung 1975;76:190-9.

Jain SC, Agarwal M. Effect of chemical mutagens on level of Ascorbic acid in Trigonella species. Acta Bot Indica 1987; 15:187-9.

Kar UC, Mahapatra BK, Patnaik SN. Induced macromutants in Sesamum indicum L. Plant Sci Res 1995;17:21-8.

Karthika R, Lakshmi BS. Effect of gamma rays and EMS on two varieties of Soybean. Asian J Plant Sci 2006;5:721-4.

Khan MR, Qureshi AS, Syed AH, Ibrahim M. Genetic variability induced by gamma irradiation and its modulation with Gibberellic acid in M2 generation of chickpea (Cicer arietinum L.). Pak J Bot 2005;37:285-92.

Khan S, Goyal S. Improvement of mungbean varieties through induced mutations. Afr J Plant Sci 2009;3:174-80.

Kozgar MI, Goyal S, Khan S. EMS induced mutational variability in Vigna radiata and Vigna mango. Res J Bot 2011;6:31-7.

Kumar A, Mishra MN. Effect of gammarays, EMS and NMU on germination, seedling vigour, pollen viability and plant survival in M1 and M2 generation of Okra (Abelmoschus esculentus (L.) Moench). Adv Plant Sci 2004;17:295-7.

Mahandjiev A, Kosturkova G, Mihov M. Enrichment of Pisum sativum gene resources through combined use of physical and chemical mutagens. Isr J Plant Sci 2001;49:279-84.

Mensah JK, Obadoni BO, Akomeah PA, Ikhajiagbe B, Ajibolv J. The effects of sodium Azide and colchicines treatments on morphological and yield traits of Sesame seed (Sesamum indicum L.). Afr J Biotechnol 2007;6:534-8.

Nazir AW,TariqAB, Ansari MY. Sodium azide induced variability in chick pea. (Cicer arietinum L.). Soc Plant Res India 2005; 18:105-7. 
Nerkar YS. Studies on the Induction of Mutations in Lathyrus sativus with Special Reference to the Elimination of the Neurotonic Principle. Ph.D. Thesis, IARI, New Delhi; 1970.

Pathak HC, Patel MS. Sensitivity of upland rice genotypes to gamma radiation. IRRN 1988;13:16-23

Rai R. Morphological and Cytogenetical studies of Gamma Irradiated Guai (Cyamopsis tetragonataub) Ph.D. Thesis, Banaras Hindu University; 1971.

Santos IS. Reduction of sensitivity to Co 60 gamma rays in Phaselolus aureus Roxb, through pre or post irradiation heat treatment of the seeds. Rad Bot 1961;5:263-71.

Sareen S, Koul AK. Mutation breeding in improvement of Plantago ovata Forsk. Indian J Genet 1999;59:337-44.

Siddiq EA, Swaminathan MS. Enhanced mutation induction and recovery caused by Nitrosoguanidine in Oryza saliva. Indian J Genet Plant Breed 1968;28:297-300.

Singh AK, Singh RM. Mutagenic effectiveness and efficiency of gamma rays, EMS and their synergistic effects in mung bean (Vigna radiata) L. (Wilczek). Crop Sci 2007;34:198-202.

Singh VV, Ramkrishana K, Arya RK. Induced chemical mutagensis in cowpea (Vigna unguiculata L.) Walp. Indian J Genet 2006;66:312-5.

Srivastava P, Marker S, Pandey P, Tiwari ZD. Mutagenic effects of sodium Azide on the growth and yield characteristics in wheat (Triticum aestivum L. Em. Thell). Asian J Plant Sci 2011;10:190-201.

Tai YS, Bragg J, Meinhardt SW. Functional characterization of ToxA and molecular identification of its intracellular targeting protein in wheat. Am J Plant Physiol 2007;2:76-89.

Thapa CB. Effect of acute exposure of gamma rays on seed germination and seedling growth of Pinus kesiya Gord and P. Wallichiana A.B. Jacks. Our Nat 2004;2:13-7.

Toker C, Uzen B, Canci H, Ceylan FO. Effects of gamma irradiation on the shoot length of Cicer seeds. Radiat Phys Chem 2005;73:365-7. 